\title{
Teaching the Biology of Gender, Sex, and Sexuality Leads to a Marked Increase in Acceptance of the Theory of Evolution by Natural Selection
}

Nathan H. Lents*

Department of Sciences, John Jay College, 445 W. 59th Street, New York, NY 10019, USA

\begin{abstract}
Biology education in the U.S. is under threat due to resistance to the principles of modern evolutionary theory. Although religious and cultural prejudices heavily influence this resistance, poor understanding of evolutionary theory itself is at least partly responsible. Thus, coherent and aggressive strategies are needed in order to rectify this poor understanding and properly educate the next generation of the electorate and its policy makers. Herein, we examine acceptance of evolutionary concepts among students in a majors-level introductory biology course and those in a gender studies course on sex, gender, and sexuality. Through pre- and post-course surveys, we measured the change in their acceptance. Surprisingly, students in the gender studies course consistently displayed greater improvement in their acceptance of evolutionary theory than the biology students, despite only tangential coverage of these topics in the gender studies course and substantial coverage of them in the biology course. These results provide evidence that one strategy for advancing the proper education of biology and natural history is throughteaching of the biological basis of reproduction and sexuality, topicsthat exhibit a high level of student interest and uniquely convey the effects and consequence of evolutionary forces such as natural and sexual selection, adaptation, mutation, and genetic drift.
\end{abstract}

Keywords: Teaching evolution; Gender; Sexual reproduction; Acceptance of evolution

\section{Introduction}

The field of biology education is under threat in the United States from select school boards, religious institutions, elected civic leaders, and parents of school children regarding the proper teaching of evolution, the grand unifying theory of all of biology [1,2]. Although federal and state courts have generally sided with the scientific community when the issue of the teaching of evolution has been litigated, science educators can play an important role by addressing the root cause of this ongoing controversy: poor understanding of the theory and mechanisms of evolution by the general public [3]. To that end, innovative and engaging teaching materials, strategies, and pedagogies are needed [4,5]. Much effort has been placed into developing resources for teaching the principles and mechanisms of topics such as natural selection in the context of general biology courses at all levels [6-11]. These efforts are sure to have positive effects on the understanding of evolution by science students as the overwhelming complexity of evolution on the macro-scale is tackled in discreet and concrete units that are comprehensible and resonant.

However, another approach is also helpful. While understanding the mechanisms of concepts such as natural or sexual selection may seem daunting to students whose major is not biology, exploring the consequences may not be. Further, there is evidence to suggest that some students that are resistant to accept the biological origins of life raise their defenses when evolution and natural are taught explicitly, even if they earn high grades [12]. Thus, an alternative strategy is simply to make connections to evolutionary processes and consequences while teaching courses and topics that are not explicitly focused on natural selection, mutation, drift, etc. In other words, it may be effective to teach about evolution without announcing it, so that resistant students are led to maintain an open mind [13].

In this study, we made use of a survey instrument for assessing student acceptance of evolutionary theory that had previously been validated and published [6]. We then measured the acceptance of evolution among students before and after taking a course on the biology of gender, sex, and sexuality, a course within the gender studies program at John Jay College with no biology course prerequisites.
Although some increase in the acceptance of evolution is naturally expected after such a course, we observed a striking degree of increased acceptance of evolutionary theory in the post-course survey. For perspective, we compared this result to the differences observed in students before and after taking Modern Biology 2 - a majors-level introductory biology class that explicitly devotes nearly one-half of the courses to evolution, natural selection, phylogeny, and natural history.

To our great surprise, we found that students in the gender studies course improved in their acceptance of evolutionary theory to a much higher degree than students in the majors-level biology course. While beginning the course with a similar level of acceptance to that of the science-major students, the gender studies students ended the course in a state of near unanimous strong support for the biological theory of evolution. These results reveal that sometimes the best way to teach evolution to resistant students is to do so implicitly, rather than explicitly, within courses where the products and consequences of evolution can be readily incorporated.

\section{The Two Comparison Groups}

Information about the two courses being compared is as follows. The gender studies course was entitled Gen-255: The Biology of Gender, Sex, and Sexuality and ran in the spring semester of 2011. Twenty-six students began the course and took the "pre" survey on the first day of class. Twenty-one students were present at the final exam and took the "post" survey. The biology course was entitled Bio-104: Modern Biology II and ran in the spring of 2010. Forty-nine students, split between two sections taught by the same instructor, began the course and took the "pre" survey on the first day of class. Fifty-two students

${ }^{*}$ Corresponding author: Nathan $\mathrm{H}$. Lents, Department of Sciences, John Jay College, 445 W. 59th Street, New York, NY 10019, USA; Tel: 646-557-4504; E-mail: nlents@jjay.cuny.edu

Received January 15, 2013; Accepted March 27, 2013; Published April 04, 2013

Citation: Lents NH (2013) Teaching the Biology of Gender, Sex, and Sexuality Leads to a Marked Increase in Acceptance of the Theory of Evolution by Natural Selection. J Phylogen Evolution Biol 1: 105. doi:10.4172/2329-9002.1000105

Copyright: @ 2013 Lents $\mathrm{NH}$, et al. This is an open-access article distributed under the terms of the Creative Commons Attribution License, which permits unrestricted use, distribution, and reproduction in any medium, provided the original author and source are credited. 
were present for the final exam and took the "post" survey at that time. Students that dropped either course at any point are not included in this analysis, and only survey responses from those students that took both the "pre" and "post" survey were considered.

The topics covered by each course are shown in table 1 , broken down weekly, as taken directly from the course syllabus provided to the students at the beginning of the course. Of note for this study, the explicit coverage of evolution, speciation, and natural selection is conspicuous in the biology course, while these same topics are covered more implicitly in the gender studies course. In addition to a variety of articles, the principle texts for the gender studies course were Roughgarden (2008), Judson (2004), and Fausto-Sterling (2000), while the sole text for the biology course was Campbell (2008). Both courses were taught by the same instructor, the author of this manuscript.

\section{The Survey Instrument}

The pre- and post-course survey instruments consist of sixteen statements that students are asked to report their level of agreement with on a scale of one to five, where "one" corresponds to strongly agree and "five" corresponds to strongly disagree. The statements are organized into several categories. First, there are three "control questions" which probe beliefs regarding the age of the earth and movement of the great land masses. These questions reveal hardened rejection of modern scientific thought regarding the natural history of the planet and have shown in the validation of the survey instrument to be fairly impervious to education about evolution and thus score similarly in pre- and post-intervention surveys [6]. The next three questions probe the "fixity" of species, or the notion that species of living things on earth have changed over time. By comparison, these questions tend to elicit less polarized values than the control questions and are subject to change upon education about the terrestrial history of life. Next come three questions that explicitly ask about acceptance of "evolution," "natural selection," and "Darwinian theory," respectively. These questions dissect feelings of acceptance and resistance triggered from those particular words. Finally, this section of the survey ends with four questions regarding the evolution of the human species from earlier species, which specifically include the words "evolved," "primates," "Darwin," and "natural selection," again in an effort to dissect resistance triggered by these specific words.

While most questions in the first section of the survey are such that "1-strongly agree" indicates acceptance of evolutionary theory and " 5 -strongly disagree" indicates rejection thereof, some have been "inverted" and indicate the opposite. This is done to help validate the survey, measure the consistency of student responses, and reveal possible confusion about question terms. These "inverted" questions are essentially questions that support creationism, fixity of species, or a young earth. However, for the data analysis, we invert the value of the answer choices to maintain " 1 " as a pro-evolution response and so forth.

In the second section of the survey, there are four questions asking students how well they assess their own understanding of evolution, selection, and the word, "theory." In the post-course survey only, there is a question asking students if they have spoken with friends or family about evolution as a result of topics they have read or heard about in the course. Finally, there is a seven-choice question that asks students to circle the statement that best represents their opinion about evolution by natural selection. These seven choices came from open-ended responses recorded from student populations during the development of the survey and are presented in a random order with respect to their level of resistance or acceptance of evolutionary theory. The entire text of the survey instruments can be found here: (PRE-survey Instruments and POST-Survey Instruments).

\section{Results-Acceptance of Evolution}

In examining the survey results between the two groups, we begin by considering only the thirteen questions that probe acceptance of evolution. We found that the two groups are markedly similar in their acceptance of evolution before the respective courses began. As shown in figure 1, the average "agreement" value of both groups for each question was strikingly similar, as we had previously seen among different student populations in the validation of the survey instrument. Further, because a response of three indicates "neither agree, nor disagree," we can conclude that both student populations are generally supportive of evolution. However, a further analysis of the survey responses indicate that $10-11 \%$ of the total individual survey responses were "disagree" or "strongly disagree," for the pro-evolution statements, and "agree" or "strongly agree," for the anti-evolution statements (Table 2). Further, $16 \%$ and $22 \%$, respectively, of the survey responses indicated neither agreement nor disagreement with the survey statements. Taken together, these results indicate that both groups had ample room for changes in their acceptance of evolution as they undertook the courses at hand.

Following the course, post-surveys were given, results were tabulated, and comparisons made. As shown in figure 2, for every question, both groups showed some improvement in their acceptance of the tenants of modern evolution theory, as one would expect.

\begin{tabular}{|l|l|}
\hline Week & Topics Covered: Gen-255 \\
\hline 1 & genetic recombination and sexual dimorphism in animals \\
\hline 2 & sexual behaviors and roles in animals \\
\hline 3 & scientific though on human sexes: early vs. modern \\
\hline 4 & human embryonic sexual development and anatomy \\
\hline 5 & meiosis, gametogenesis, fertilization \\
\hline 6 & human menstrual cycle \\
\hline 7 & fertility, contraception , pregnancy, abortion \\
\hline 9 & male sexual function and fertility, biology of testosterone \\
\hline 10 & current science of gender differences \\
\hline 11 & role of women in science: historical vs. modern \\
\hline 12 & hermaphoditism, gender/sex switching in animals \\
\hline 13 & gender identity, Intersex, sexual (re)assignment \\
\hline 14 & same-sex sexuality in nature, new definitions of gender \\
\hline
\end{tabular}

Topics Covered: Bio-104

principles of natural selection; evolution of populations

origin of species; history of life on earth

phylogenetics; classification; biodiversity

evolution/properties of domains and kingdoms of life

evolution, form, classification of microbes

evolution, form, classification of plants

evolution, form, classification of animals

animal body plan, tissues, organ systems

circulatory, respiratory, and immune systems

osmoregulation, urinary system, homeostasis

endocrine system, reproduction, development

motor, skeletal, digestive systems

nervous and sensory systems

population and community ecology; adaptation

Table 1: The topics covered by Gen-255 and Bio-104. This chart lists the course topics of these two courses, as listed in the official course syllabi for spring 2011 


\begin{tabular}{|c|c|c|}
\hline & Bio-104 & Gen-255 \\
\hline Total responses & & \\
\hline \% of 5s: & 633 & 337 \\
\hline \% of 4s: & 4.7 & 4.5 \\
\hline \% of 3s: & 6.2 & 5.6 \\
\hline \% of 2s: & 39.0 & 28.8 \\
\hline \% of $1 \mathrm{s:}$ & 33.6 & 38.9 \\
\hline
\end{tabular}

Table 2: Generalized Survey Results: In an effort to generalize the entire survey results, all individual survey responses were considered together. Counts of each response were made and percents were calculated. The percent of " $1 \mathrm{~s}$ " and " $2 \mathrm{~s}$ " are summary indicators of acceptance of evolution while the percent of " $4 \mathrm{~s}$ " and " $5 \mathrm{~s}$ " are indicators of disagreement.

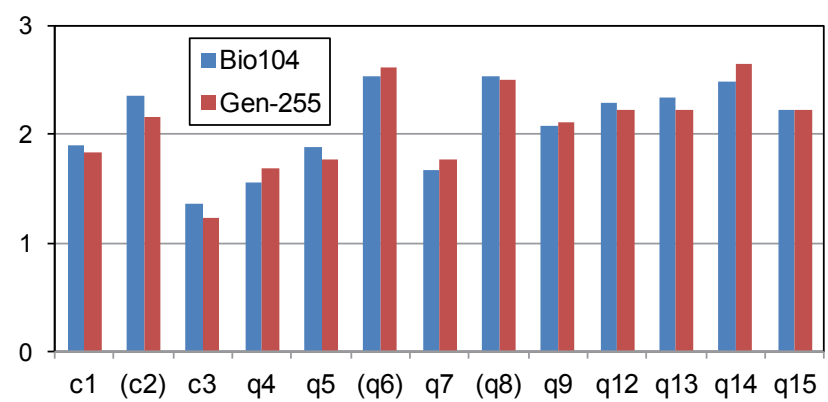

Figure 1: The baseline acceptance of evolution was similar in both groups. Average score were calculated for the survey questions probing acceptance of current evolutionary theory. Individual question numbers are listed on the horizontal axis. Numbers in parentheses represent statements where agreement indicates rejection of evolutionary theory and thus, values for these questions were "inverted" prior to analysis, to maintain the interpretation scheme that low values indicate high acceptance.

However, the students in the gender studies coursed showed an even greater improvement than the students in the evolution-heavy biology course, an effect seen in almost every single question. We performed the unpaired student's t-test on the data from these surveys and found that none of the changes in survey results from the Bio104 group reached statistical significance to a p-value less than $0.05 \%$ (data now shown). However, on four questions, c2, q4, q12, and q13, the change in survey results were statistically significant for the Gen 255 group with p-values of $0.047,0.000057,0.045$, and 0.024 , respectively (Figure 2A). Thus, the improvement in acceptance of the evolutionary theory observed in the Gen255 was both substantial and statistically verifiable.

For a generalized look at the overall attitudes, we again analyzed the total survey responses (Figure 2B). Once again, this analysis revealed that both groups came into greater acceptance of evolution through their respective courses, but the gender studies group made the biggest gains, despite starting in very similar places. Interestingly, the gender studies students even showed change in their responses to the control questions which proved resistant to significant change in previous validations of this survey among biology students (Figure 2A, questions $\mathrm{c} 1$, and $\mathrm{c} 2$ ).This is indeed surprising, given that geologic age and geologic change were in no way part of the reading, lectures, or discussions of the gender studies course, while covered explicitly in the biology course.

In order to probe how students' attitudes toward evolution may have changed during the semester, the final question on the post-course survey asked the students, "Has your view about evolution and natural selection changed after learning about it in this class?" The students could choose from eight choices listed in (Table 3). These choices were written during the previous construction and validation of the survey instrument and were formulated based upon the most frequently observed answers given by students to this question in an open-response format. The results for question 20 are shown in (Figure 3). There is one substantial difference in the response rate observed between the two different groups. The largest group of Gen255 students reported that they now feel more confident in their beliefs about evolution because of what they learned in the class. In fact, the percentage of students who selected that choice was twice as large among the Gen255 students than Bio104 students. This is remarkable because neither group had substantial education about evolution previously and Bio104 is a course that is explicitly dedicated to the teaching of evolution, while Gen255 does so only implicitly.

The data shown in figures 2 and 3 clearly indicate that the student attitudes in the gender studies course became more favorable toward evolution after learning about the biology of sex, sexuality, and reproduction. However, in addition to the group-level analyses, we also endeavored to link individuals to their pre- and post-surveys answers and assess how many students actually changed their views on a given question after having taken the course. To do this, we compared students' pre- and post-surveys and considered any downward

$\mathbf{A}$
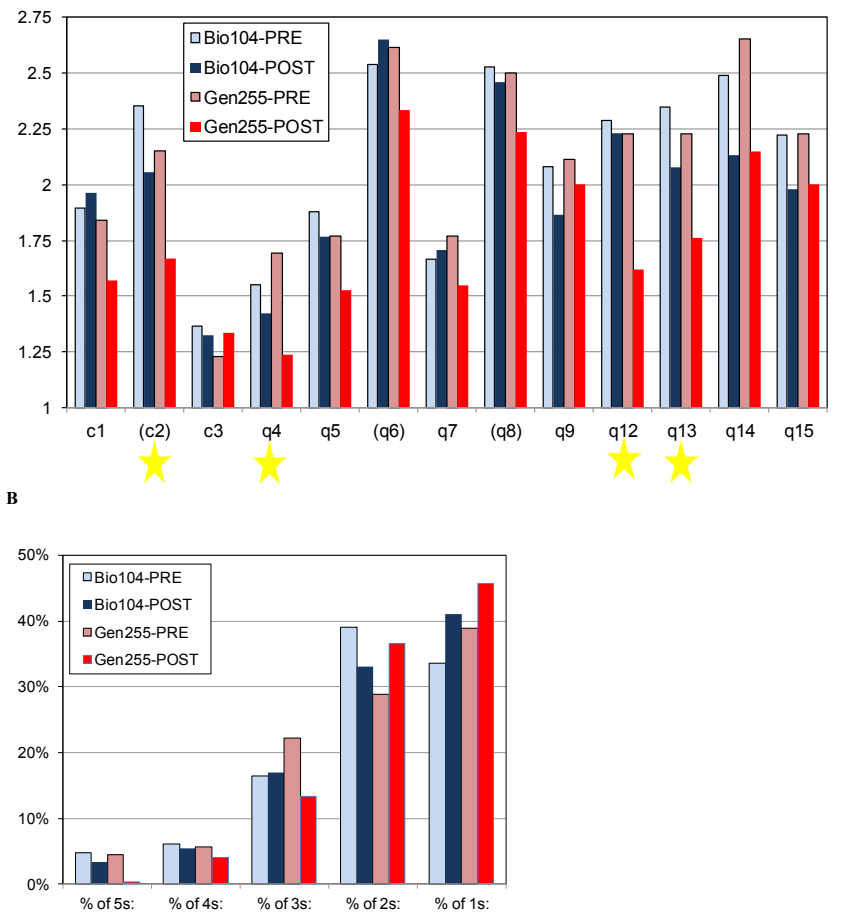

Figure 2: The change in acceptance of evolution after completing the courses.

A) Average score were calculated for the survey questions probing acceptance of current evolutionary theory, before and after the respective course. Individual question numbers are listed on the horizontal axis. Numbers in parentheses represent statements where agreement indicates rejection of evolutionary theory and thus, values for these questions were "inverted" prior to analysis, to maintain the interpretation scheme that low values indicate high acceptance. The yellow stars () indicate a statistically significant change in survey results in the Gen-255 group with respective p-values of $0.047,0.000057,0.045$, and 0.024 , respectively. No statistically significant differences $(p<0.05$ by students unpaired t-test) were found in the Bio-104 group.

B) In an effort to generalize the entire survey results, all individual survey responses were considered together. Counts of each response were made and percents were calculated. 


\begin{tabular}{|c|l|}
\hline Choice & Answer \\
\hline A & Not really. Although I now know more about the details and implications of natural selection, it is a theory that I have always strongly supported. \\
\hline B & Not really. I have never believed in evolution and I still don't \\
\hline C & Somewhat. I guess I always supported the theory of evolution, but now I have a more solid grounding about what it means. \\
\hline D & Somewhat. I was doubtful about it before and now I really don't think that it all happened like scientists think it did. \\
\hline E & Somewhat. I was doubtful before, but now I am more open-minded about it. \\
\hline F & Yes. I was a little unsure about it before, but now that I have seen it more spelled out, I definitely don't believe in evolution. \\
\hline G & Yes, I was doubtful about it before, but now I can see that the scientific evidence that support evolution by natural selection is very strong. \\
\hline H & Although I feel like I know more about it now, I am still not quite sure. \\
\hline
\end{tabular}

Table 3: Choices for question 20 on the post-course survey, "Has your view about evolution and natural selection changed after learning about it in this class?"

movement in the survey response toward more acceptance of evolution (or an upward movement for the anti-evolution statements) as an "improvement," regardless of whether the response changed from, for example, five to four, three to one, or five to two: all counted as an improvement. Using this framework, we calculated the percent of students that "improved" in their responses to each question and the data is shown in (Figure 4). As shown, both courses exhibited a marked improvement of student attitudes toward evolution, but the effect was especially dramatic for students in the gender studies course. In fact, on five of the thirteen questions, half or more of the students increased acceptance of the scientific theory of evolution and natural selection.

Our survey also contained three questions regarding the science conversations in the personal lives of the students. Question \#10 probes whether students have recently had discussions with friends or family about evolution. As shown in figure 5, the post-course survey revealed that students in the gender studies students answered more affirmatively after taking the course, suggesting that the course itself may have prompted students to have those discussions. Meanwhile, the pre/post differences were negligible among the biology students. Perhaps the most dramatic difference in change was seen in the responses to the statement, "I feel that I could adequately explain why the concept of evolution by natural selection is called a 'theory.'," question \#16. Students in the gender studies course self-reported much less confidence in their understanding at the beginning of the course, but much more confidence at the end. Yet again, this is surprising because the biology course includes explicit coverage of what the term "scientific theory" means, while the gender studies course covers this cursorily, if at all, in the course readings only.

\section{Discussion}

In this study, two groups of students at the same college were compared. One group enrolled in a majors-level biology course that places a large focus on evolution, natural history, and the mechanisms of selection. The other course enrolled students from a diversity of majors in a gender studies course covering the biology of gender, sex, and sexuality. Perhaps surprisingly, the two groups tested very similarly on an entrance survey regarding their beliefs about evolution. Even more surprising, the students in the gender studies course showed a more dramatic change toward more evolution-accepting beliefs at the end of the course than did the students in the biology course that had a great deal of explicit focus on evolution. These two courses were taught by the same instructor.

In order to ensure that the differences we observed were reflective of a true difference in the student attitudes, we performed a student's $\mathrm{t}$-test on the data that formed figure $2 \mathrm{~A}$, a test that is robust and strict for detecting significant difference in data such as survey results. We found no differences in the pre- and post-survey results that rose to the level of statistical significance at $\mathrm{p}<0.05$. However, for four different questions, we did find significant differences in the post-course survey results for the Gen255 group.
The other mechanism through which we sought differences is found in figure 4 . We paired the pre- and post-survey responses for specific students and counted "improvement" events, expressing them as a percentage of the total. This technique mitigates the effect of any initial differences between the two groups by counting all changes regardless of their magnitude. This does assume, however, that neither group has a substantial difference in how many students are already in the extreme end of the spectrum towards which you are looking for change (in this case, the "1s" on the survey response). If one group were closer to that end of the spectrum, there could be less room for improvement; the analysis would be biased against them. This does not appear the case here for two reasons. First, the groups were not substantially different in their starting points, a point clearly demonstrated in figure 2 and (Table 2). Secondly, as shown in table 2, the Gen255 students actually had MORE responses of 1 on the survey and thus if there was any systemic bias in detecting increased acceptance by this technique, it would be against the Gen 255 group. And yet, we were able to detect substantially greater improvement in the acceptance of evolution in the Gen 255 group using most of the survey questions. For this reason, we feel confident in drawing tentative conclusions using these conservative analyses.

There are many possible underlying reasons why a class on the biology of sex would have a more dramatic effect on acceptance of evolution than a class that more explicitly covers evolution. Perhaps the most obvious is that a course that has evolution as a major and explicit learning goal might engender more concerted resistance to the course content, right from the start. Students may "put their defenses up" right as the course begins and remain resistant to contemplating the material deeply. On the other hand, a course on the biology of gender and sex might not necessarily illicit such a knee-jerk response and students are allowed to explore the course content with a more open mind. A second explanation is that the kinds of students in the gender studies course are somehow different and more susceptible to a change in attitude on the subject. Although possibly more interesting, this explanation has no empirical support other than the perhaps conventional wisdom that students self-selecting into a gender studies course are more "open-minded" than average. However, that the students scored nearly identically in the pre-course evolution survey somewhat argues against this point.

Another possible explanation is that the subject matter of this class, which includes sexual and asexual reproduction, genetic recombination, sexual dimorphism, sexual selection, and sexual/ reproductive behaviors in animals, might help open the minds of students about evolution even more than an explicit evolutionary biology course. This is conceivable because topics of reproductive biology are of great interest to college students. Possibly unbeknownst to first learners, this field harbors some of the most tangible and striking examples of the consequences of natural and sexual selection as well as mutation, drift, and other evolutionary forces. Thus, the combination 


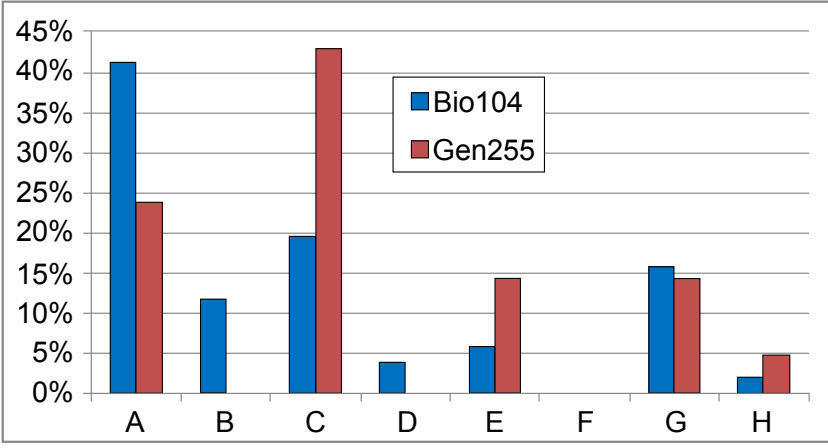

Figure 3: Response rates for the choices on question 20 of the post-course survey among the two student groups. Response choices are listed in table 3.

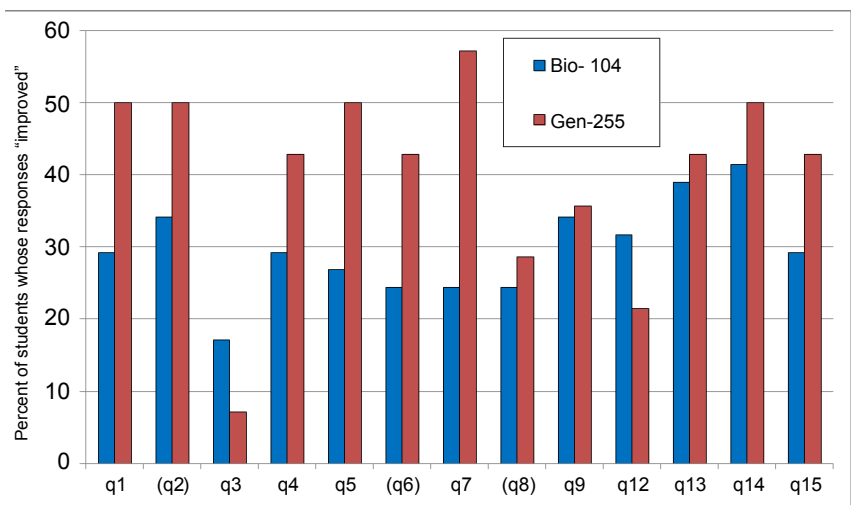

Figure 4: Changes in beliefs toward evolution in individual students.

Average scores were calculated for the survey questions probing acceptance of current evolutionary theory, before and after the respective course. Individual question numbers are listed on the horizontal axis. Numbers in parentheses represent statements where agreement indicates rejection of evolutionary theory and thus, values for these questions were "inverted" prior to analysis, to maintain the interpretation scheme that low values indicate high acceptance. Responses from the same student were compared before and after the course and changes in responses were counted. Results are presented as a percentage of the total students in the cohort.

of naïve student interest and resonant examples of evolution's work provide an excellent environment for changing attitudes toward the proven scientific reality of evolutionary change. If such a reality is born out in further studies, biology educators would have great reason to consider adding these topics to the biology curriculum in our efforts to teach students the modern evolutionary theory.

\section{References}

1. Asimov I (1984) The "Threat" of Creationism. The New York Times Magazine 90-101.

2. Ayala FJ (2008) Science, evolution, and creationism. Proc Natl Acad Sci USA 105: 3-4.

3. Miller JD, Scott EC, Okamoto S (2006) Public acceptance of evolution. Science 313: 765-766.

4. Alberts B, Labov JB (2004) From the National Academies: Teaching the Science of Evolution. Cell Biol Educ 3: 75-80.

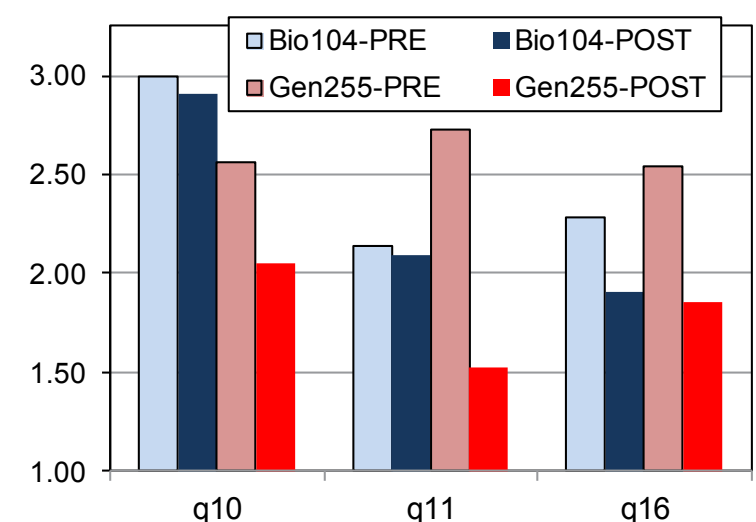

Figure 5: Results on additional survey questions concerning the process of science.

Group average scores were calculated for the survey questions probing the self-reporting of understanding and interest in the theory of evolution by natural selection.

5. Alters BJ, Nelson CE (2002) Perspective: Teaching evolution in higher education. Evolution 56: 1891-1901.

6. Lents NH, Cifuentes OE, Carpi A (2010) Teaching the Process of Molecular Phylogeny and Systematics: A Multi-Part Inquiry-Based Exercise. CBE Life Sci Educ 9: 513-523.

7. Perry J, Meir E, Herron JC, Maruca S, Stal D (2008) Evaluating two approaches to helping college students understand evolutionary trees through diagramming tasks. CBE Life Sci Educ 7: 193-201.

8. Lombrozo T, Thanukos A, Weisberg M (2008) The importance of understanding the nature of science for accepting evolution. Evolution 1:290-298.

9. Robbins JR, Roy P (2007) The Natural Selection: Identifying Student Misconceptions through an Inquiry-Based, Critical Approach to Evolution. Am Biol Teach 69: 460-466.

10. Alles DL (2001) Using evolution as the framework for teaching biology. Am Biol Teach 63: 20-23.

11. Baum DA, Smith SD, Donovan SS (2005) Evolution: The Tree-Thinking Challenge. Science 310: 979-980

12. Clough MP (1994) Diminish students' resistance to biological evolution. Am Biol Teach 56: 409-415.

13. Scott EC, Branch G (2009) Don't call it "Darwinism”. Evolution 2: 90-94 